\title{
Peroxisomal Proliferation in Rat Liver and Essential Fatty Acid Deficiency
}

\author{
Eric Rabetafika, ${ }^{1}$ Jean-Paul CARreaU, ${ }^{1}$ and Claude Le GoAsCoGnE ${ }^{2}$,* \\ 'Unité INSERM 347, and ${ }^{2}$ Unité INSERM 488, Hôpital de Bicêtre, 94276 Bicêtre Cedex, France
}

(Received November 22, 2001)

Summary The effects of essential fatty acid (EFA) deficiency were studied on male Wistar rats membrane lipid composition, enzyme activities and proliferation of liver peroxisome by feeding the animals, during 4 weeks, with fat free diets supplemented or not with a peroxisome proliferator, clofibrate (CLO).

In deficient (E) goup, peroxisomal membrane was characterized by higher level of total de novo synthesized unsaturated (n-9 and n-7 series) fatty acids and lower content of EFA (n-6 and n-3 series) and exhibited cholesterol (CHOL) to phospholipids (PLs) ratio diminution compared with that of control (C) group. Co-administration of CLO with the fat-free diet (EC group) enhanced the membrane uptake of $n-9$ fatty acids. Slight increase of membrane dihydroxyacetone-phosphate acyl-transferase (DHAP-AT) and decrease of palmitoyl-CoA synthetase activities were found in E group which featured normal-shaped peroxisomes.

In EC group, enzyme inductions of peroxisomal pamitoyl-CoA oxidase and palmitoyl-CoA synthetase were slightly higher and significantly lower respectively compared with those of C group treated with CLO (CC group) whereas activity of DHAP-AT was stable. Identical marked proliferation of peroxisomes were observed in both groups.

It is inferred that, despite the parallel alterations of membrane lipid composition and of enzyme activities of peroxisomes upon 4 weeks of EFA deficient-diet, the biogenesis and proliferation of the organelles were independently processed at a normal level. The possibility of homeostatic regulation and its physiological importance were discussed.

Key Words: essential fatty acid, deficiency, peroxisomes, clofibrate, proliferation

*To whom correspondence should be addressed. Unité 488 INSERM, Hôpital de Bicêtre, 80, rue du Général Leclerc, 94276 Bicêtre Cedex, France (E-mail: lego@kb.inserm.fr; Fax: 33-145-21-1940). 
Peroxisomes are ubiquitous cytoplasmic organelles found in almost all cellular types of vertebrate animals. In mammalian liver, most of the peroxisomal enzymes act at lipid catabolism or anabolism reactions including oxidation of very-long-chain fatty acids, prostaglandin and leukotriene as well as some steps of synthesis of ether-phospholipids (PLs), bile acids, and cholesterol (CHOL) [1]. Many are the indications supporting the hypothesis that the composition of fatty acids of the diet could be of fundamental importance in the assembling mechanism of peroxisomal membrane. Newly formed peroxisomes are well known to be generated by the budding of preexisting ones [2]. PL incorporation into peroxisomal membrane required intracellular lipid transfer from endoplasmic reticulum (ER) which involved transport proteins such as non-specific PL transfer protein [3] and would be facilitated by frequently observed spatial proximity with ER $[4,5]$. Peroxisomal membrane protein synthesis also preceded that of matrix proteins, suggesting that peroxisome biogenesis could be initiated by new membranes [6].

In our previous comparative study between peroxisomal and microsomal membranes in rat liver, distinct physiological impacts were induced by essential fatty acid (EFA) deficiency [7]. Because proliferation of peroxisomes has the particular feature to be inducible and visualizable by microscopy [8], we presented and discussed here the results of an extensive study of combined clofibrate (CLO) treatment with EFA deprivation of the diet effects on membrane properties of this organelle.

\section{MATERIALS AND METHODS}

Animals. Male Wistar rats (R. Janvier, Le Genest-Sainte-Isle, France) were caged under $22^{\circ} \mathrm{C}$ and $12 \mathrm{~h}$ light-dark cycle into four groups $(n=4)$ after weaning (21 days of age). The first two groups were fed, ad libitum for 4 weeks, either standard (C group) or fat-free diet (E group), while the other two were served, respectively, the two same diets to which $0.30 \% \mathrm{w} / \mathrm{w}$ of CLO were supplemented on day 14 of the experiments (CC and EC groups).

Basal diet composition (UAR, Villemoisson, France) was (g per 100g): vitamin- and fat-free casein, 26.5\%; corn starch, 31\%; saccharose, 31.6\%; cellulose, 2.5\%; mineral mixture, $4.5 \%$; vitamin mixture, $2 \%$; DL-methionine, $0.4 \%$ and for fatty diets, $1 \%$ soybean oil was added.

The fatty acids composing the soybean oil were converted to methyl esters and analyzed by gas-chromatographic procedures as described in the following section. Soybean oil contained (\% by weight): C16:0, 10.6\%; C18:0, 3.5\%; C18:1, 24.2\%; C18:2, 54\%; $\mathrm{C} 18: 3,5.4 \%$.

Processing for light and electron microscopy. Small pieces of liver were cut and fixed for $1 \mathrm{~h}$ at $0-4^{\circ} \mathrm{C}$ with $1.5 \%$ glutaraldehyde in $30 \mathrm{~mm} \mathrm{NaOH}$-Pipes buffer, $\mathrm{pH} 7.2$, containing $8 \%$ sucrose. After rinsing in the same buffer, specimens were incubated in the alkaline diaminobenzidine medium for cytochemical visualization of catalase [9], followed by osmication and embedding in Epon 812. Two millimeter thick semi-thin sections were counterstained with Giemsa. Ultrathin sections were examined without counterstaining in a Siemens Elmiscop 101 electron microscope. 
Isolation of peroxisomes and assay of marker enzymes. Peroxisomes were prepared and purified from livers of normal and treated rats homogenized in the buffer containing $0.25 \mathrm{~m}$ sucrose, $5 \mathrm{~mm}$ Mops, $1 \mathrm{mM}$ EDTA, and $0.1 \%(\mathrm{v} / \mathrm{v})$ ethanol, $\mathrm{pH}$ 7.4. Homogenates were subfractionated into peroxisome-enriched fractions by $19,000 \mathrm{~g}$-centrifugation for $15 \mathrm{~min}$ according to the method of Ghosh and Hajra [10]. The pellets called L-fraction were thereafter purified by ultracentrifugation on Nycodenz density gradient [11]. The purity of the resultant peroxisomal fractions was ascertained as previously described [10] by the relative specific activities, with respect to the whole homogenate fractions of marker enzymes-microsomal glucose-6-phosphatase, mitochondrial succinate-cytochrome $c$ reductase, and lysosomal acid phosphatase. Percent of contamination, in all cases of diets, was found to be less than $5 \%$.

Membranes were isolated from the purified peroxisomal fraction by using the carbonate procedure of Fujiki et al. [12].

Peroxisomal enzyme activities were analysed as described previously: for cyanideinsensitive palmitoyl-CoA oxidase, by monitoring the spectrophotometric absorption of NADH [13], for dihydroxyacetone-phosphate acyl-transferase (DHAP-AT), by measuring the labeled lipid formed from ${ }^{14} \mathrm{C}$-DHAP [14], and for palmitoyl-CoA synthetase, by using $\mathrm{U}-{ }^{14} \mathrm{C}$-palmitic acid and coenzyme $\mathrm{A}$ as substrates [15].

Lipid analysis of peroxisomal membrane. After extraction of total lipids according to the method of Bligh and Dyer [16], thin layer chromatography on Silica Gel plates G60 F-254 (Merck, Darmstadt, Germany) was used to isolate total PLs and elution was made with $n$-hexane/petroleum ether/acetic acid, 80:20:2 (by volume). The major components of PLs, phosphatidylcholine (PC), phosphatidylethanolamine (PE), phosphatidylinositol (PI), phosphatidylserine (PS), and sphingomyeline (Sph), were separated with chloroform/methanol/methylamine, 13:6:1.5 (by volume).

Methyltransesterification method described by Carreau and Dubacq [17] is performed prior to fatty acid compositon analysis on gas liquid chromatography apparatus (DELSI 30 C, Suresnes, France) [7].

Quantity of PLs was obtained by inorganic phosphate dosage [18]. Amount of membrane CHOL was determined as described previously [19].

\section{RESULTS}

Percentage distribution of the ratios of 5 main PL classes and CHOL to total PLs $(\mathrm{mol} / \mathrm{mol})$ in peroxisomal membrane are shown in Table 1. Irrespective of the nature of the diet, PC and PE represented about $55 \%$ and $20 \%$ of total PLs, respectively. EFA deficiency (E group) slightly increased PI level compared with that of control group. Addition of CLO into the diet of control and EFA-deficient rats produced a slight increase in Sph $(\simeq+50 \%)$ and $\mathrm{PE}(\simeq+20 \%)$ percentages and a significant decrease in PI levels $(\simeq-70 \%$ in CC group and $\simeq-60 \%$ in EC group). In E group, a diminution of about $20 \%$ was observed in the CHOL-to-PLs ratio. A fall of the same order occurred in the CC group vs $\mathrm{C}$ whereas the value is stable in the EC group vs. E.

As shown in Table 2, fat deprivation of the diet (E group) resulted in low concentra- 
Table 1. The ratio of phospholipid composition and cholesterol to total phospholipids of peroxisomal membrane in the rat liver.

\begin{tabular}{lcccccc}
\hline \multirow{2}{*}{ Animals } & \multicolumn{5}{c}{ Phospholipid (\% mol/mol $)$} & \multirow{2}{c}{$\begin{array}{c}\text { CHOL/PLs } \\
(\mathrm{mol} / \mathrm{mol})\end{array}$} \\
\cline { 2 - 6 } & PE & PC & Sph & PS & PI & \\
\hline Control (C) & $21.9 \pm 1.7$ & $56.4 \pm 4.5$ & $5.6 \pm 0.8$ & $3.9 \pm 0.3$ & $12.0 \pm 1.1$ & $0.196 \pm 0.009$ \\
C+clofibrate (CC) & $25.8 \pm 2.6^{\mathrm{a}}$ & $57.7 \pm 5.9$ & $8.0 \pm 0.6^{\mathrm{a}}$ & $4.6 \pm 0.5$ & $3.6 \pm 0.3^{\mathrm{a}}$ & $0.165 \pm 0.008^{\mathrm{a}}$ \\
EFA-deficient (E) & $21.6 \pm 1.5$ & $56.2 \pm 4.7$ & $4.3 \pm 0.7$ & $3.3 \pm 0.2$ & $14.7 \pm 0.6^{\mathrm{b}}$ & $0.150 \pm 0.008^{\mathrm{b}}$ \\
E+clofibrate (EC) & $23.5 \pm 2.8^{\mathrm{c}}$ & $57.9 \pm 3.8$ & $7.0 \pm 0.5^{\mathrm{c}}$ & $5.1 \pm 0.4^{\mathrm{c}}$ & $6.3 \pm 0.4^{\mathrm{c}}$ & $0.147 \pm 0.007$ \\
\hline
\end{tabular}

Values are expressed as mean $\pm \mathrm{SD}$ of 4 experiments. A value for $p<0.05$ was taken to indicate significance: ${ }^{\mathrm{a}}\left(\mathrm{CC}\right.$ vs. C); ${ }^{\mathrm{b}}\left(\mathrm{E}\right.$ vs. C); ${ }^{\mathrm{c}}(\mathrm{EC}$ vs. E).

Table 2. Effect of clofibrate on fatty acid composition of rat liver peroxisomal membrane.

\begin{tabular}{lcccc}
\hline Animals & $\begin{array}{c}\text { Control } \\
(C)\end{array}$ & $\begin{array}{c}\text { C+clofibrate } \\
(C C)\end{array}$ & $\begin{array}{c}\text { EFA deficient } \\
(\text { E })\end{array}$ & $\begin{array}{c}\text { E+clofibrate } \\
(\text { EC })\end{array}$ \\
\hline Fatty acid & & & & \\
$16: 0^{1}$ & $22.5 \pm 2.1^{2}$ & $22.5 \pm 0.9$ & $20.5 \pm 1.0$ & $23.3 \pm 0.9^{\mathrm{c}}$ \\
$16: 1(\mathrm{n}-9)$ & $0.8 \pm 0.1$ & $0.5 \pm 0.1$ & $1.0 \pm 0.1$ & $0.7 \pm 0.1$ \\
$16: 1(\mathrm{n}-7)$ & $2.1 \pm 0.2$ & $1.3 \pm 0.2^{\mathrm{a}}$ & $6.4 \pm 0.8^{\mathrm{b}}$ & $2.1 \pm 0.1^{\mathrm{c}}$ \\
$18: 0$ & $25.5 \pm 0.9$ & $19.6 \pm 0.6^{\mathrm{a}}$ & $29.7 \pm 0.8^{\mathrm{b}}$ & $17.3 \pm 0.3^{\mathrm{c}}$ \\
$18: 1(\mathrm{n}-9)$ & $6.9 \pm 0.5$ & $15.7 \pm 0.7^{\mathrm{a}}$ & $11.9 \pm 0.5^{\mathrm{b}}$ & $20.0 \pm 1.1^{\mathrm{c}}$ \\
$18: 1(\mathrm{n}-7)$ & $2.6 \pm 0.4$ & $2.0 \pm 0.1^{\mathrm{a}}$ & $4.0 \pm 0.8$ & $2.3 \pm 0.1^{\mathrm{c}}$ \\
$18: 2(\mathrm{n}-6)$ & $11.7 \pm 0.5$ & $6.3 \pm 0.1^{\mathrm{a}}$ & $4.4 \pm 0.4^{\mathrm{b}}$ & $1.7 \pm 0.1^{\mathrm{c}}$ \\
$20: 3(\mathrm{n}-9)$ & $1.4 \pm 0.1$ & $4.0 \pm 0.1^{\mathrm{a}}$ & $7.8 \pm 1.3^{\mathrm{b}}$ & $17.2 \pm 0.5^{\mathrm{c}}$ \\
$\gamma 20: 3(\mathrm{n}-6)$ & $2.4 \pm 0.5$ & $3.0 \pm 0.2$ & $1.3 \pm 0.3^{\mathrm{b}}$ & $0.7 \pm 0.1^{\mathrm{c}}$ \\
$20: 4(\mathrm{n}-6)$ & $11.1 \pm 0.4$ & $15.7 \pm 0.2^{\mathrm{a}}$ & $7.5 \pm 0.1^{\mathrm{b}}$ & $9.9 \pm 0.3$ \\
$22: 5(\mathrm{n}-3)$ & $2.1 \pm 0.2$ & $1.1 \pm 0.1^{\mathrm{a}}$ & - & - \\
$22: 6(\mathrm{n}-3)$ & $11.3 \pm 0.7$ & $8.4 \pm 0.4^{\mathrm{a}}$ & $5.3 \pm 0.3^{\mathrm{b}}$ & $4.3 \pm 0.7^{\mathrm{c}}$ \\
\hline
\end{tabular}

${ }^{1}$ Number of carbons: number of double bonds, n-position of the first double bond related to methyl end (n). ${ }^{2}$ Values are expressed in $\%(\mathrm{w} / \mathrm{w})$ as mean $\pm \mathrm{SD}$ of 4 experiments. A value for $p<0.05$ was taken to indicate significance: ${ }^{\mathrm{a}}(\mathrm{CC} v s . \mathrm{C}) ;{ }^{\mathrm{b}}(\mathrm{E} v s . \mathrm{C}) ;{ }^{\mathrm{c}}(\mathrm{EC} v s . \mathrm{E})$.

tions of essential unsaturated fatty acids (UFAs) such as linoleate (C18:2 n-6) and arachidonate $(\mathrm{C} 20: 4 \mathrm{n}-6)$ in total PLs of the peroxisomal membrane and contributed to the predominance of incorporation of C18:1n-9 and C20:3n-9 (endogeneous UFAs) both considered as the major EFA deficiency markers [20].

CLO induced elevation of the peroxisomal membrane levels of C18:1 n-9 and C20:3 $\mathrm{n}-9$ as well as C20:4 n-6 in CC group vs. C and led to overload of the C18:1 n-9 and C20:3 n-9 contents in EC group vs. E.

Moreover, $\mathrm{C} 20: 3 \mathrm{n}-9 / \mathrm{C} 20: 4 \mathrm{n}-6$ ratios $(\mathrm{SEM} \pm \mathrm{SD}, n=4)$ run from $1.04 \pm 0.05$ to $1.73 \pm 0.15$ in $\mathrm{E}$ and $\mathrm{EC}$ groups, respectively $v s$. $0.12 \pm 0.01$ in control animal indicating high index of deficiency compared with the threshold value of 0.5 in serum of EFA-deficient rat [20].

Average unsaturations of peroxisomal membrane fatty acids were measured (Table 3) by the double bond index (DBI) which indicates the sum of the product of each UFA percentage by the number of double bond of the same fatty acid. Unsaturation index 
(USI) was obtained from DBI divided by the sum of percent of saturated fatty acids. In E group, DBI and USI significantly decreased by about $25 \%$ and $30 \%$, respectively, compared with that of control group. With CLO treatment, slight increases of USI were observed in CC group vs. C $(\simeq+10 \%)$ and in EC group $v s . \mathrm{E}(\simeq+40 \%)$ and in the latter group the value was closely the same as that of control rat.

Table 3. Double bond and unsaturation indices of fatty acid composition of rat liver peroxisomal phospholipids.

\begin{tabular}{lcccc}
\hline Animals & $\begin{array}{c}\text { Control } \\
(C)\end{array}$ & $\begin{array}{c}\text { C+clofibrate } \\
(C C)\end{array}$ & $\begin{array}{c}\text { EFA deficient } \\
(\text { E) }\end{array}$ & $\begin{array}{c}\text { E+clofibrate } \\
(\text { EC) }\end{array}$ \\
\hline DBI & $169.1 \pm 11.0$ & $171.3 \pm 5.2$ & $120.2 \pm 9.1^{\mathrm{b}}$ & $146.9 \pm 7.9^{\mathrm{c}}$ \\
USI & $3.52 \pm 0.10$ & $4.06 \pm 0.25^{\mathrm{a}}$ & $2.39 \pm 0.25^{\mathrm{b}}$ & $3.39 \pm 0.20^{\mathrm{c}}$ \\
\hline
\end{tabular}

Values are expressed in \% (w/w) as mean \pm SD of 4 experiments. A value for $p<0.05$ was taken to indicate significance: $\left.{ }^{\mathrm{a}}(\mathrm{CC} v s . \mathrm{C}) ;{ }^{\mathrm{b}}(\mathrm{E} v s . \mathrm{C}){ }^{\mathrm{c}}{ }^{(\mathrm{EC}} v s . \mathrm{E}\right)$.
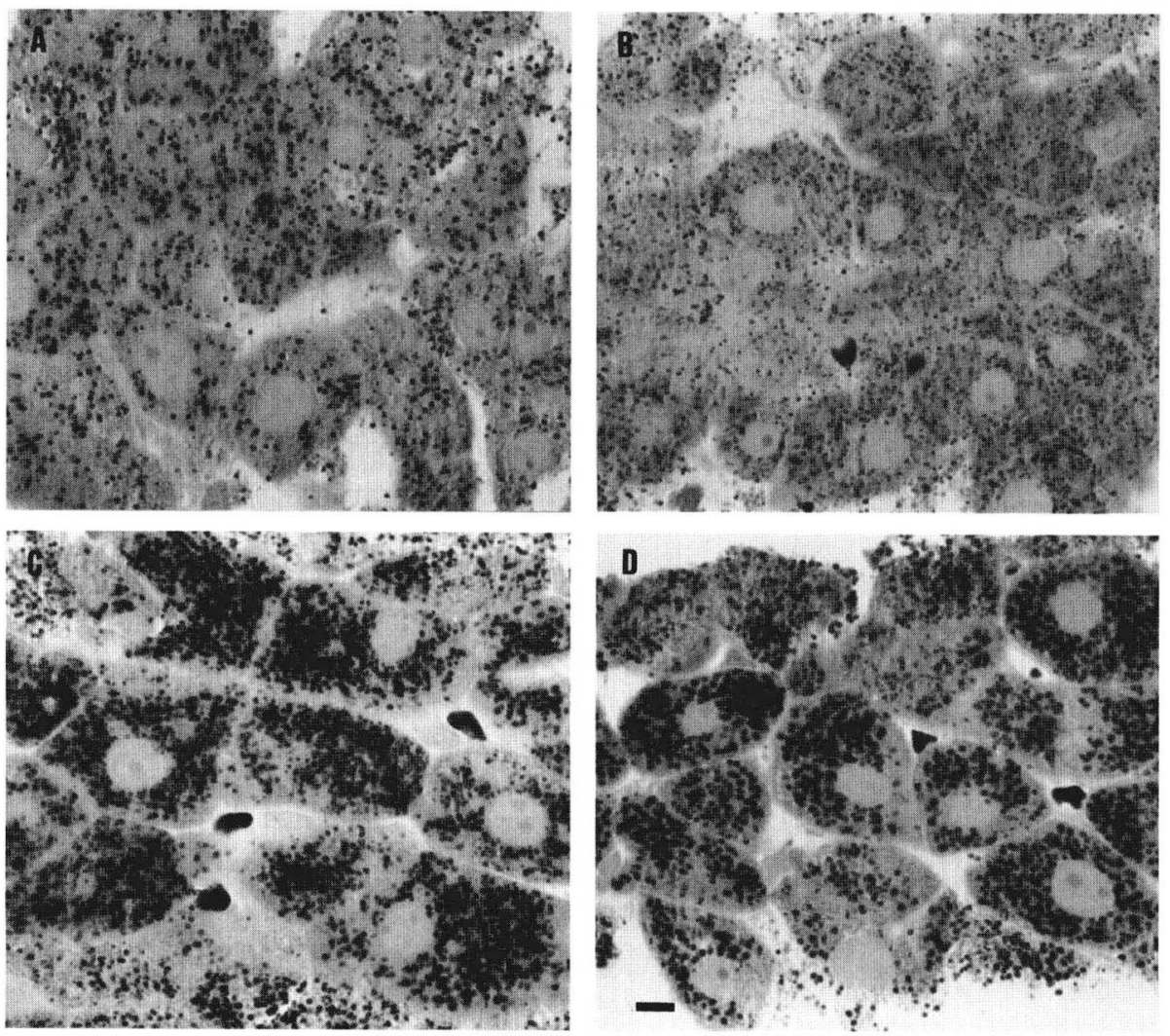

Fig. 1. Effect of proliferators on rat liver peroxisomes and essential fatty acid deficiency: light microscopic cytochemical demonstration. Control untreated (A); fatty acid deprived (B); control plus clofibrate (C); fatty acid deprived plus clofibrate (D). Bar, $10 \mu \mathrm{m}$. 
Number and morphology of liver peroxisomes of the rats were observed under light (Fig. 1) and electron (Fig. 2) microscopy. No significant difference was found in these parameters in E group (Figs. 1B and 2B) vs. control (Figs. 1A and 2A). Less numerous but enlarged mitochondria, well established as the main manifestation of EFA deficiency in the liver tissue [21], was retrieved here (Fig. 2B). A recovery of the normal size was however noted in EC group (Fig. 2D).

In both $\mathrm{CC}$ and $\mathrm{EC}$ groups $v s$. control (Fig. $2 \mathrm{C}$ and $\mathrm{D}$ ), the peroxisomes showed the known structural anomalies induced by CLO [22] such as shape irregularity and the presence of some elongated tails along with the greater size of the organelle. No significant difference was found in the liver peroxisomes density in rats fed either with normal or fatfree diet (Fig. 1C and D).
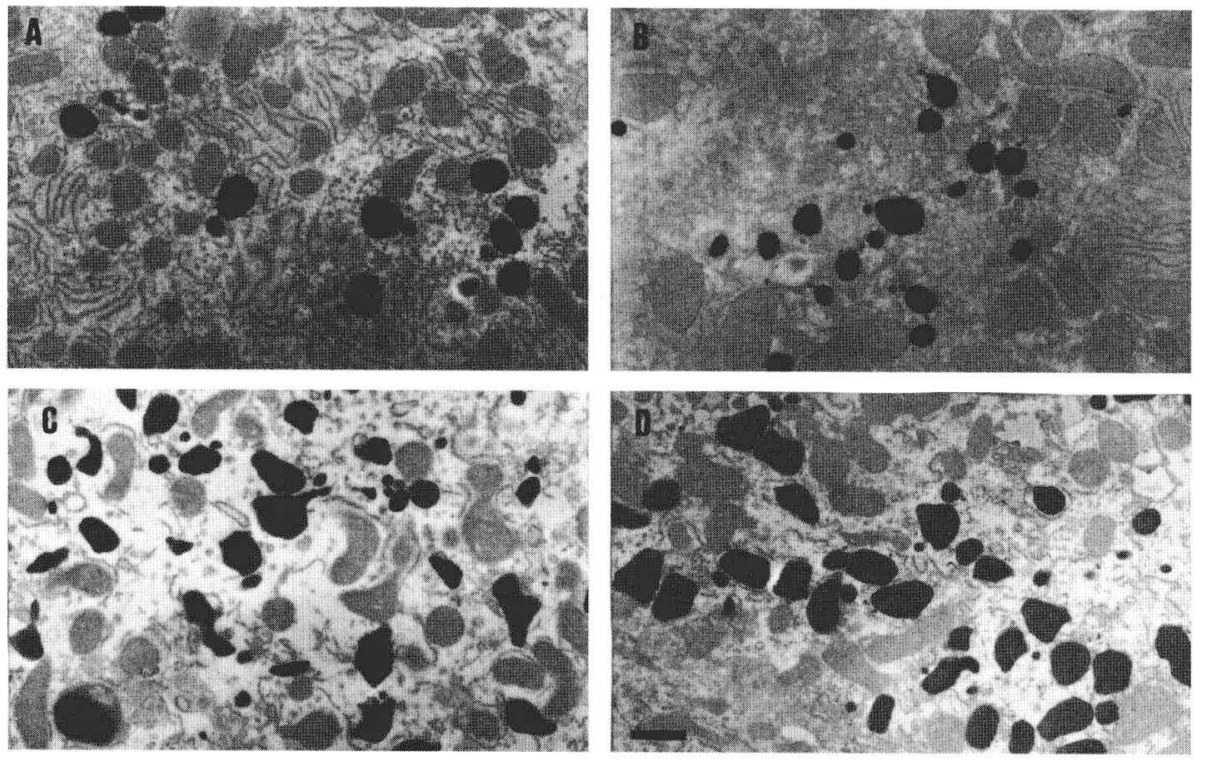

Fig. 2. Effect of proliferators on rat liver peroxisomes and essential fatty acid deficiency: electron micrograph. Control untreated (A); fatty acid deprived (B); control plus clofibrate (C); fatty acid deprived plus clofibrate (D). Bar, $1 \mu \mathrm{m}$.

Table 4. Enzyme activities in purified peroxisomal fraction of the rat liver.

\begin{tabular}{lcccc}
\hline Animals & $\begin{array}{c}\text { Control } \\
(\mathrm{C})\end{array}$ & $\begin{array}{c}\text { C+clofibrate } \\
(\mathrm{CC})\end{array}$ & $\begin{array}{c}\text { EFA-deficient } \\
(\mathrm{E})\end{array}$ & $\begin{array}{c}\text { E+clofibrate } \\
(\mathrm{EC})\end{array}$ \\
\hline DHAP-AT & $2.46 \pm 0.70$ & $2.31 \pm 0.80$ & $3.80 \pm 1.0^{\mathrm{b}}$ & $2.43 \pm 1.02^{\mathrm{c}}$ \\
Palmitoyl-CoA synthetase & $0.21 \pm 0.04$ & $1.98 \pm 0.15^{\mathrm{a}}$ & $0.08 \pm 0.02^{\mathrm{b}}$ & $1.27 \pm 0.10^{\mathrm{c}}$ \\
Palmitoyl-CoA oxidase & $0.09 \pm 0.01$ & $0.65 \pm 0.04^{\mathrm{a}}$ & $0.11 \pm 0.01^{\mathrm{b}}$ & $0.75 \pm 0.04^{\mathrm{c}}$ \\
\hline
\end{tabular}

Unit of enzyme activity is $\mathrm{nmol} / \mathrm{min} / \mathrm{g}$ liver for DHAP-AT, and $\mathrm{mmol} / \mathrm{min} / \mathrm{g}$ liver for palmitoylCoA synthetase and palmitoyl-CoA oxidase. Results are expressed as means \pm SD of 4 experiments. A value for $p<0.05$ was taken to indicate significance: ${ }^{\mathrm{a}}(\mathrm{CC} v s . \mathrm{C}){ }^{\mathrm{b}}(\mathrm{E} v s . \mathrm{C}){ }^{\mathrm{c}}{ }^{\mathrm{c}}(\mathrm{EC} v s . \mathrm{E})$. 
The results of some peroxisomal matrix and membrane-associated enzyme activities are presented in Table 4. In E group, DHAP-AT activity was increased by about $50 \%$ compared with that of control group. With CLO treatment the activity had fallen by approximately $50 \%$ in EC group vs. E. Activity of palmitoyl-CoA synthetase in E group was found to be 2.5-times less active than in control group. CLO induced 9-fold increase of the enzyme activity in CC group vs. $\mathrm{C}$ and to a lesser extent of about 6-fold in EC group vs C. CLO treatment expectedly led to palmitoyl-CoA oxidase induction of about 6-fold in CC vs C. In EC group vs. C, a slight to be detectable on electronic micrograph but significant increase (about 8.3 -fold) was shown.

\section{DISCUSSION}

The major changes in PL composition induced by the diets concerned PC, PI and Sph. Not so many data by others are available about lipid composition of peroxisomal membrane [23, 24]. The results of Kyrklund and Meijer [23] about the variation in PE, PC, PI and CHOL contents after CLO treatment were consistent with ours. Minor differences in amplitude could be explained by their use of another rat strain and/or divergent experimental conditions in the peroxisomal isolation procedure. The low rate of PI incorporation into peroxisomal membrane in $\mathrm{CC}$ group might be the reflect of a preferential incorporation of endogeneous polyUFAs into $\mathrm{PE}$ and $\mathrm{Sph}$ that had a slight percentage increase and also into PC. Indispensable role of these PLs is emphasized by their properties in regulating membrane fluidity and interaction of protein with polar head group of the PLs [24, 25]. It was also suggested that PI-dependent transduction signal could be induced by CLO [26], thus possibly affecting the PI turnover and its incorporation into peroxisomal membrane. However, the fact that EFA deficiency elevated PI levels in E group vs. C and even in CLO-treated rats (EC vs. CC) would be in favour of the former hypothesis.

As previously observed in other cellular and subcellular compartment membranes [27, 28], EFA-deficiency mainly decreased C18:2n-6 and C20:4n-6 and in compensation increased $\mathrm{C} 18: 1 \mathrm{n}-9$ and $\mathrm{C} 20: 3 \mathrm{n}-9$ contents. The microsomal $\Delta 9$ and $\Delta 6$ desaturase activities are known to be inducible either by EFA-deficiency or CLO addiction [29, 30]. Combining of both treatments therefore artificially overloaded Mead acid in the peroxisomal membrane. Examination of the USI in E group allows us to state that endogeneous polyUFAs only provided partial compensation of the low EFAs contents. As previously demonstrated by the use of spin labeling probe in the microsomal membrane of rat liver [31], decrease of USI correlated to less fluid membrane under EFA-deficient condition. If an USI-dependent diminution effect on membrane fluidity of peroxisome was expected, it is worth noting that it was found to be counterbalanced by the low rate of CHOL, another regulating factor of the fluidity [32]. In this way, the integrity of viscotropic property of the membrane might be regulated to have a constant value. This was in keeping with the ranging of the USI value in EC group close to that of control group. Besides, in CC group the membrane is in evidence altered to be more fluid as experimentally confirmed [33]. However, fine tuning in the interaction between lipid membrane and enzyme proteins was 
probably regulated by double bond position of UFAs and by polarity of PL head groups $[24,25,31]$. This would in part explain additionally to variation in membrane fluidity, how DHAP-AT and palmitoyl-CoA synthetase activities were differentially affected by the various diets. Conversely, translocation and incorporation of palmitoyl-CoA oxidase into the subcellular matrix either with proliferator treatment or not were preserved. This is in support to the previous hypothesis of palmitoyl-CoA synthetase activity being modulated by membrane lipid composition variation in EFA-deficient groups. Intracellular very-long-chain fatty acid uptake would have been blocked if an inhibition in gene expression of the latter enzyme had occurred [34] and hence would have dramatically inhibited the peroxisomal oxidizing activity. The induction of palmitoyl-CoA oxidase by CLO was established to be a stimulation of peroxisomal functioning [35]. Therefore, the higher activity of palmitoyl-CoA oxidase in EC group vs. CC was probably aimed at the degradation of the abnormally elevated concentration of Mead acid which so far has not been reported to have physiological function. In parallel, normal feature was shown on biogenesis and induced proliferation of peroxisomes in EC group. In CLO-treated groups, one way to explain the pleiomorphy of peroxisomes aside from the nascent burgeoning effect (Fig. 2C and D) is the change in interaction of protein with lipids but this is still a matter of discussion $[22,36]$. Whilst EFA depletion of the diet implied a number of biochemical and physiological changes along the duration of the experimentation, the peroxisomal biogenesis and proliferation processes were maintained at a normal level. Endogeneous UFAs played a compensating role as constitutive lipids of peroxisomal membrane in response to the lacking EFAs. Additional support to this is the physiological maintenance role by peroxisome [37] in retroconversion and shortening of long and verylong-chain fatty acids, thus contributing to recycling of membrane PLs during the phase of proliferation.

In conclusion, under EFA deficiency the crucial functionality of peroxisome with respect to metabolism of membrane lipid would constrain an homeostatic regulation on the membrane PUFAs composition such that a level of integrity was preserved for a normal biogenesis and proliferation of the organelle. Long-term consequence of the dietary treatments on the peroxisomal viability remained however to be determined.

We are thankful to M. Gouézou for technical assistance in electron microscopic preparations.

\section{REFERENCES}

1. Van den Bosch, H., Schutgens, R.B.H., Wanders, R.J.A., and Tager, J.M. (1992): Biochemistry of peroxisomes. Annu. Rev. Biochem., 61, 157-197.

2. Lazarow, P.B., and Fujiki, Y. (1985): Biogenesis of peroxisomes. Annu. Rev. Cell Biol., 1, 489-530.

3. Wirtz, K.W.A. (1997): Phospholipid transfer proteins revisited. Biochem. J., 324, 353-360.

4. Zaar, K., and Gorgas, K. (1985): Peroxisome-endoplasmic reticulum aggregates in the duck uropygial gland. Eur. J. Cell Biol., 38, 322-327.

5. Achleitner, G., Gaigg, B., Krasser, A., Kainersdorfer, E., Kohlwein, S.D., Perktold, A., Zellnig, G., and Daum, G. (1999): Association between the endoplasmic reticulum and mitochondria of yeast facilitates interorganelle transport of phospholipids through membrane contact. Eur. J. Biochem., 264, 545-553. 
6. Baumgart, E., Völkl, A., Hashimoto, T., and Fahimi, H.D. (1989): Biogenesis of peroxisomes: Immunocytochemical investigation of peroxisomal membrane proteins in proliferating rat liver peroxisomes and in catalase-negative membrane loops. J. Cell Biol., 108, 2221-2232.

7. Rabetafika, E., and Carreau, J-P. (1997): Peroxisome and essential fatty acid deficiency. J. Clin. Biochem. Nutr., 23, 155-163.

8. Hess, R., Stäubli, W., and Riess, W. (1965): Nature of the hepatomegalic effect produced by ethyl chlorophenoxyisobutyrate in the rat. Nature, 208, 856-858.

9. Angermüller, S., and Fahimi, H.D. (1981): Selective cytochemical localization of peroxidase, cytochrome oxidase and catalase in rat liver with 3,3-diaminobenzidine. Histochemistry, 71, 33-44.

10. Ghosh, M.K., and Hajra, A.K. (1986): A rapid method for the isolation of peroxisomes from rat liver. Anal. Biochem., 159, 169-174.

11. Verheyden, K., Fransen, M., Van Veldhoven, P.P., and Mannaerts, G.P. (1992): Presence of small GTP-binding proteins in the peroxisomal membrane. Biochim. Biophys. Acta, 1109, 48-54.

12. Fujiki, Y., Hubbard, A.L., Fowler, S., and Lazarow, P.B. (1982): Isolation of intracellular membranes by means of sodium carbonate treatment: Application to endoplasmic reticulum. J. Cell Biol., 93, 97-102.

13. Lazarow, P.B., and de Duve, C. (1976): A fatty acyl-CoA oxidizing system in rat liver peroxisomes; Enhancement by clofibrate, a hypolipidemic drug. Proc. Natl. Acad. Sci. U.S.A., 73, 2043-2046.

14. Singh, H., Usher, S., and Poulos, A. (1989): Dihydroxyacetone phosphate acyltransferase and alkyldihydroxyacetone phosphate synthase activities in rat liver subcellular fractions and human skin fibroblasts. Arch. Biochem. Biophys., 268, 676-686.

15. Krisans, S.K., Mortensen, R.M., and Lazarow, P.B. (1980): Acyl-CoA synthetase in rat liver peroxisomes. J. Biol. Chem., 255, 9599-9607.

16. Bligh, E.G., and Dyer, W.J. (1959): A rapid method of total lipid extraction and purification. Can. J. Biochem. Physiol., 37, 911-917.

17. Carreau, J.P., and Dubacq, J.P. (1978): Adaptation of a macro-scale method to the micro-scale for fatty acid methyl transesterification of biological extracts. J. Chromatogr., 151, 384-390.

18. Kai, M., and Hawthorne, J.N. (1966): Incorporation of injected $\left({ }^{32} \mathrm{P}\right)$ phosphate into the phosphoinositides of subcellular fraction from young rat brain. Biochem. J., 98, 62-67.

19. Zlatkis, A., and Zak, B. (1969): Study of a new cholesterol reagent. Anal. Biochem., 29, 143-148.

20. Holman, R.T. (1971): Essential fatty acid deficiency, in Progress in the Chemistry of Fats and Other Lipids, ed. by Elmsford, Pergamon Press, New York, Vol. 9, pp. 275-348.

21. Stancliff, R.C., Williams, M.A., Utsumi, K., and Packer, L. (1969): Essential fatty acid deficiency and mitochondrial function. Arch. Biochem. Biophys., 131, 629-642.

22. Yamamoto, K., and Fahimi, D.H. (1987): Three-dimensional reconstruction of a peroxisomal reticulum in regenerating rat liver: Evidence of interconnections between heterogeneous segments. $J$. Cell Biol., 105, 713-722.

23. Kyrklund, T., and Meijer, J. (1994): Lipid composition of liver peroxisomes isolated from untreated and clofibrate-treated mice and rats. Comp. Biochim. Physiol., 109, 665-673.

24. Crane, D.I., and Masters, C.J. (1986): The effect of clofibrate on the phospholipid composition of the peroxisomal membrane. Biochim. Biophys. Acta, 876, 256-263.

25. Omodeo-Salé, F., Lindi, C., Palestini, P., and Masserini, M. (1991): Role of phosphatidylethanol in membranes. Effects on membrane fluidity, tolerance to ethanol, and activity of membrane-bound enzymes. Biochemistry, 30, 2477-2482.

26. Xia, X., and Serrero, G. (1999): Inhibition of adipose differentiation by phosphatidylinositol 3kinase inhibitors. J. Cell Physiol., 178, 9-16.

27. Burr, G.O., and Burr, M.M. (1930): On the nature and role of the fatty acid essential in nutrition. $J$. Biol. Chem., 86, 587.

28. Holman, R.T. (1986): Nutritional and biochemical evidence of acyl interaction with respect to essential polyunsaturated fatty acids. Prog. Lipid Res., 25, 29-39.

29. Melin, T., and Nilsson, A. (1997): Delta-6 desaturase and delta-5 desaturase in human HepG2 cells are both fatty acid interconversion rate limiting and are upregulated under essential fatty acid deficient condition. Prostaglandins Leukot. Essent. Fatty Acids, 56, 437-442.

30. Garda, H.A., Bernasconi, A.M., Brenner, R.R., Aguilar, F., Soto, M.A., and Sotomayor, C.P. (1997): Effect of polyunsaturated fatty acid deficiency on dipole relaxation in the membrane inter-

Vol. 31, 2002 
face of rat liver microsomes. Biochim. Biophys. Acta, 1323, 97-104.

31. Christon, R., Fernandez, Y., Cambon-Gros, C., Periquet, A., Deltour, P., Léger, C.L., and Mitjavila, S. (1988): The effect of dietary essential fatty acid deficiency on the composition and properties of the liver microsomal membrane of rats. J. Nutr., 118, 1311-1318.

32. Heron, D.S., Shinitsky, M., Hershkowitz, M., and Samule, D. (1980): Lipid fluidity markedly modulates the binding of serotonin to mouse brain membranes. Proc. Natl. Acad. Sci. U.S.A., 77, 74637467.

33. Hardeman, D., Versantvoort, C., and van den Brink, J.M. (1990): Studies on peroxisomal membranes. Biochim. Biophys. Acta, 1027, 149-154.

34. Choi, J.Y., and Martin C.E. (1999): The Saccharomyces cerevisiae FATl gene encodes an acyl-CoA synthetase that is required for maintenance of very long chain fatty acid levels. J. Biol. Chem., 274, 4671-4683

35. Schon, H.J., Grgurin, M., Klune, G., Prazer, C., Marz, C., Lezenstein, E., Book, P., and Kramar, R. (1994): Effects of hypolipidaemics cetaben and clofibrate on mitochondrial and peroxisomal enzyme of rat liver. J. Pharm. Pharmacol., 46, 144-147.

36. Gorgas, K. (1982): Serial section analysis of peroxisomal shape and membrane relationships in the mouse preputial gland. Ann. N Y Acad. Sci., 386, 519-522.

37. Hayashi, H., and Takahata, S. (1991): Role of peroxisomal fatty acyl-CoA beta-oxidation in phospholipid biosynthesis. Arch. Biochem. Biophys., 284, 326-331. 